\title{
The Investigation of Punctuation in Photographic Copies of Persian Writing
}

\author{
Azam Estaji \\ Linguistics Department, Ferdowsi University of Mashhad, PO box 91779-48974, Park Square, Ferdowsi University of \\ Mashhad, Iran \\ Email: estajiz@yahoo.com \\ Ailin Firooziyan Pooresfahani \\ Linguistics Department, Ferdowsi University of Mashhad, PO box 91779-48974, Park Square, Ferdowsi University of \\ Mashhad, Iran \\ Email: Ailin_firooziyan@yahoo.com
}

\begin{abstract}
In spoken language, body language is used to show the intention of the speaker. Written language lacks such capacity and that is why punctuation, as a tool, is used to clarify spoken language features in written language and help the readers get the hidden meaning. Analyzing the punctuation used in Persian written language in photographic copies of five to eight centuries with different subjects revealed that in spite of Iranian point of view "believed the punctuation marks entered in Persian language from other languages and are imported", they exist some signs in these copies from ancient times. The data were gathered through taking photos from the original copies. Investigating the signs in these copies reveals that they have seven features of showing pause, decorating, making gap between verses, separating Arabic text from Persian, making some parts of the text prominent and showing the end of a subject. In comparison to recent texts, it is evident that nowadays authors use different tools and signs for showing the same cases. It should be taken into consideration that comma is the only sign which was present in Persian language, but nowadays is used with a different function.
\end{abstract}

Index Terms - spoken language, written language, punctuation, photographic copies

\section{INTRODUCTION}

The emersion of written language in comparison to spoken language is relatively new and is utilized as a means to save information and to refresh memory. Sentence making and punctuation are the most important rules in written language. Punctuation which is the compliment of sentence is defined as signs which reveal the author's intention and help the reader recognize the hidden meaning of the sentence. In other words, correct usage of signs in order to get the concepts in a sentence is defined as punctuation (Mansouri, 1997). In writing, body language which is the feature of spoken language, is absent, so one can use punctuation in order to clarify the meaning (Samiee, 2004).

Most of spoken languages around the world such as Persian are rhythmic and this fact will make the words of sentences more meaningful while speaking and one can change the meaning of a sentence by changing the intention and stress of a specific word. By making sure that signs are used correctly, one can avoid probable ambiguity. Otherwise the sentence will be interpreted differently; therefore, not paying attention to correct use of punctuation leads to misunderstanding (Ghorbaniyun, 2005).

Before starting the study, a brief history on the root of punctuation is given at the beginning. Then the Iranian and non-Iranian statements and views of punctuation are described followed by the Iranian belief on the use of punctuation in Persian language and also its function in this language.

From the fact that the question is how punctuations are realized in Persian language and how other languages have influence on it, the purpose of this study is to investigate the functions of different punctuation marks in photographic copies to contribute reader in getting the meaning. According to the kind of the study, the collection of the data is possible by taking photo from the original copies covering different subjects.

In general, the study attends to answer the following questions:

1) How punctuations are realized in photographic copies from fifth century to eighth century of lunar year?

2) What are the functions of these punctuations?

3) Is there any significant difference between the photographic copies with those of new writing?

4) Are there any substitutions for these punctuations in new writings?

\section{LITERATURE REVIEW}

\section{A. Punctuation}


Masaheb (1967) defines punctuation as a means of decorating the holy Quran verses in his dictionary. In other words the word punctuation is related to verses which are embellished by gold water. Moein (1995) believes that "Sajavandi" is the pioneer in this field and introduced seven signs and from that time the signs are known as punctuation and those holy books which are using these signs are called "punctuation Quorans". Also he mentions that these signs (written signs) are the ones which cause reading a text, a sense, and also writing formula in math and make differences in pronouncing the words.

\section{B. Iranian Point of View on Punctuation}

Atashparvar (1982) emphasizes using punctuation in a sentence that may help reader recognize the hidden concepts of a text. He compares punctuation with telescopic insects that not only endanger the health but also sometimes survive the people from death.

Amini (2010) mentions that one should use these signs properly, not too many not less than enough to confuse the reader and in other words as proper use may help the reader understand the meaning of sentences, on the other side improper use may cause confusion. He also states that punctuation is similar to traffic signs and both have hidden meaning, so one should learn its rules to get the meaning.

Adibsoltani (1987) who is also the researcher in investigating the punctuation introduces it as putting specific signs in texts. He believes that it is possible in two ways, one showing the logical relationship between different parts of speech of a sentence and getting the hidden meaning by another, which is general and is called "logical punctuation". The second way is delivering the sensation and personal emotion that is specific and called "stylistic punctuation". He also emphasizes that improper use of punctuation leads to confusion.

Zolfaghari (1999), like other researchers such as Yahaghi (2005), Mansouri (1997), Ahmadigivi (2001), states that using punctuation in written language is necessary. He mentions that these pauses, stresses and intonations are not realized in writing, so in order to make a text readable, one can use punctuation. He comments that these signs divide a sentence into different clauses and clarify the logical relations between parts of a sentence.

Kakhi (2000) conducts a study on punctuation function. He mentions that punctuation contributes the reader to read a text correctly and without any problems in front of others. He believes that every single sign helps the reader change his intonation based on specific function. He also exemplifies that, for instance when a reader comes to a question mark, he may choose an intonation relevant to it or he may stop and pause while facing a comma. He emphasizes that punctuation in their early time, have these important functions, but gradually there were some changes in punctuation function and those readers who read text silently will get used to these signs.

Yahaghi (2005) like Mansouri and Zolfaghari state that use of punctuation helped a better understanding of a written text and also believes that punctuation would avoid any misunderstanding.

\section{Non-Iranian Point of View on Punctuation}

Bacon (1924) as one of the religion investigators emphasizes the importance of punctuation in written texts. He examines the meaning of a part of Bible in his article named "punctuation, translation, interpretation" and focused on the utilization of this punctuation in this holy book. He believes that punctuation invigorates the text.

Salisbury (1939), one of the researchers in this field, in his paper titled "psychology of punctuation", investigates the functions of these signs. He believes that these signs are the tools that help reader in reading and relate author's concepts to each other; in other words, the author's using of punctuation reveals the logical relationships between parts of the sentences. He generally divides these relations to three categories: 1) independence of sentences from each other:2) dependence of sentences from each other: 3) the value of each sentence. He states that for each of these relations, there are certain signs that are utilized based on the relation present among sentences.

Singleton (1944) points out that understanding of punctuation in written language is related to the vision. For this reason he introduces "eye punctuation" because he believes that the reader sees these signs by his eyes and as a result will understand the text. In return, in spoken language he used the term "ear punctuation" and mentioned that phrases in spoken language are heard by ears.

Sparks (1953) believes that in order to get the hidden meaning of a text, analyzing the text and its sentence is required. He states that one can recognize the meaning easily and unconsciously without analyzing the sentence, but sometimes because of the complexity of some texts, the author should investigate each sentence and its relation to other sentences separately and punctuations are those tools which help the reader to understand the meaning correctly. Finally he states that usage of punctuation particularly in a complex text is important.

Johnson (1954) mentions that punctuation has remained the same during the time of the change in style of written language because punctuations associated with technique of speech. For instance full stop (.) which comes at the end of a declarative sentence or comma which separates a chain of sentences. He declares the appropriate use of punctuation as the delivering meaning of author.

Solomon (1990) in his paper titled, "the power of punctuation", recognizes that the function of punctuation is relevant to the author's style. He believes that those punctuations are present in written language, but are not heard. Based on his view, punctuations in written text may determine the speed, pitch and pause between words and sentences. For example, he mentions that full stop is the sign of stopping and finishing the sentence, comma decreases the speed of reading and question mark change the pitch scale. He considers punctuation as a music sign and says that as the different letters 
make distinctive features in speech, punctuation marks also play an important role in transferring the meaning of a sentence.

Mann (2003) introduces some points in facing trouble with punctuation. He knows punctuation as a means to transfer the information. He mentions that there are some problems in learning how to use punctuation that one of the most significant ones is the relevance between punctuation and syntax and the grammar.

\section{Punctuation in Persian}

Adibsoltani (1987) in his book named "the guidelines to make a book" states that punctuation has entered Persian language from overseas. He follows and explains that in ancient times, educated people in Iran were able to read the complex sciences and literary Persian books without any punctuation, but the reading of western books were difficult, that the dependence of these texts on punctuation reveal a shortcoming for languages. He believes that nowadays in European language, punctuation plays a vital role that not focusing on proper use of signs may cause misunderstanding. He also mentions that in the past there were not such problems in Persian language and in these recent 100 years these signs are entered from foreign language.

Khayam (1995) points out that for a long period of time, Persian texts were written without using any signs, while nowadays for writing different texts, the punctuation marks are utilized a lot. He emphasizes that one should pay attention to differentiate the signs from the words and also mentions that some signs may cause big problems.

Kakhi (2000) recognizes that function of punctuation in Persian language is different from European texts. He believes that because of these salient differences, there remains some limitations and that is why one should try to use the types of signs properly. He mentions that these signs are entered Persian from foreign language and stated that these signs are entered from French language for the first time and their equivalents are the same as French terms or combination of Persian and French language. In Persian sometimes both the French and Persian terms are used.

Samiee (2007) divides signs in to two categories, main signs and secondary signs. He points out that the first signs include full stop, comma, exclamation marks, semicolon, colon, underline and question mark. Apart from these signs, he believes that there are some secondary signs such as parenthesis and slash which regularly have certain meaning.

Yahaghi (2005) mentions that usage of punctuation in Persian language does not have a long history, and is common in Persian language in the current century based on western texts. He emphasizes that one should avoid using punctuation marks too many or fewer than what is needed and use signs according to sentences and Persian language structure.

\section{RESULTS}

Analyzing the data in this study is based on the punctuations of photographic copies from fifth century to eighth centuries of lunar year which includes six copies. In order to clarify the subject of the study, examples are given for each copy. Since these are historical Persian notes, they could not be translated into English and are kept original.

1)"Hedayatolmotealin Fi Teb" was written by Akhvini Bokharai in 478 lunar year which consisted of traditional medicine. The signs used in this copy are given as follows:

- The sign which is used at the top of words and count words in order to make them prominent and separate that part from others.

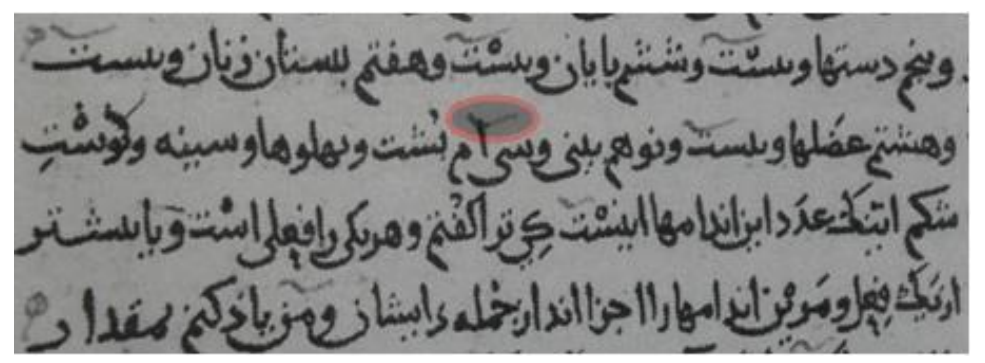

- The sign which is used to make a pause between two phrases, one at the end and one at the beginning of a line.

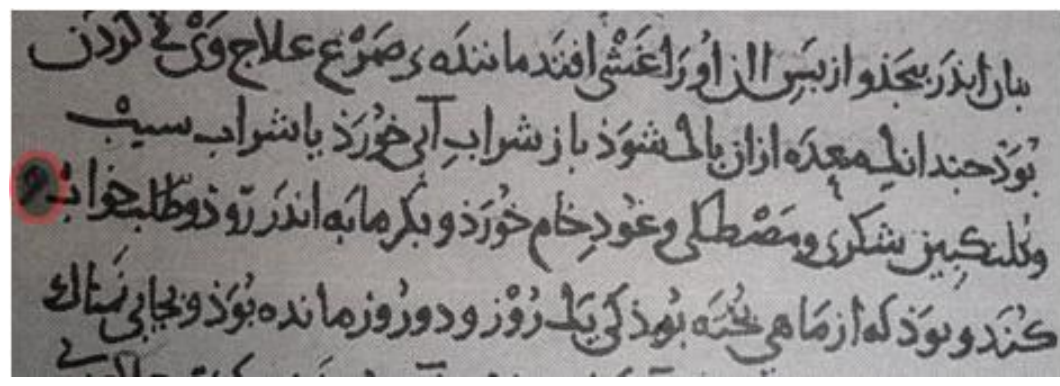


- The signs consist of three commas as a triangle along with a sign like $(\sim)$ on the top of it to show that the sentence is finished and segregate it from the other sentence.

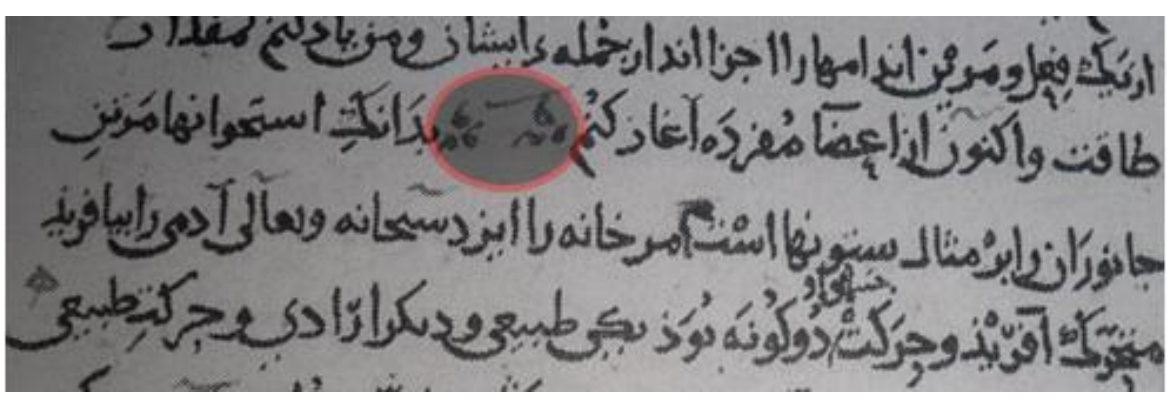

- The sign like three dots as a triangle used in order to reveal a gap and a long stop between two clauses.



- The sign which is combined of triangular dots and ( $\triangleleft$ along with $(\sim)$ on top of it to make a full stop among sentences.

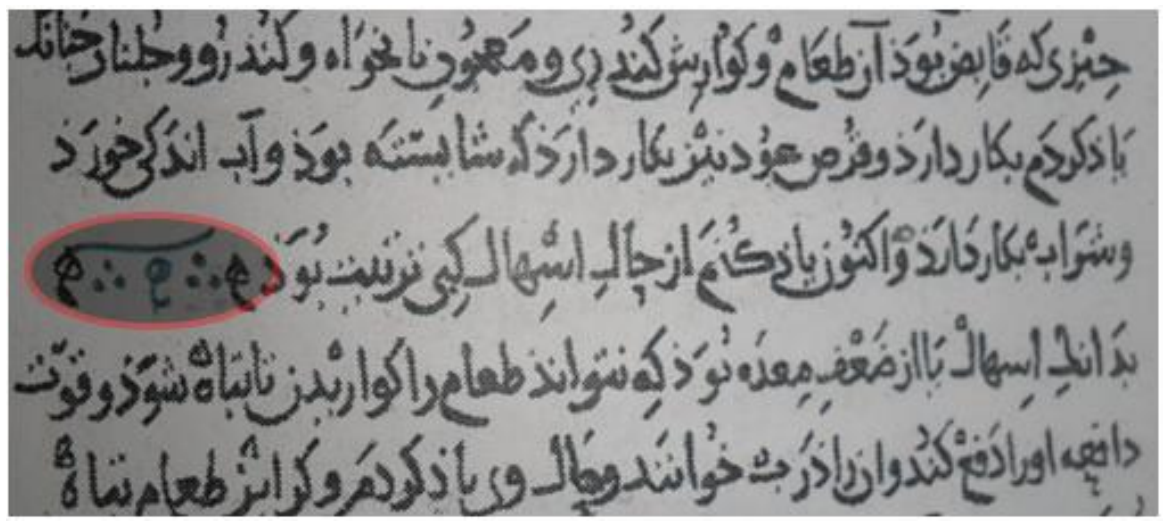

- The sign like number (5) in Persian along with $(\sim)$ at the top to gap and halt between two subjects in a text.

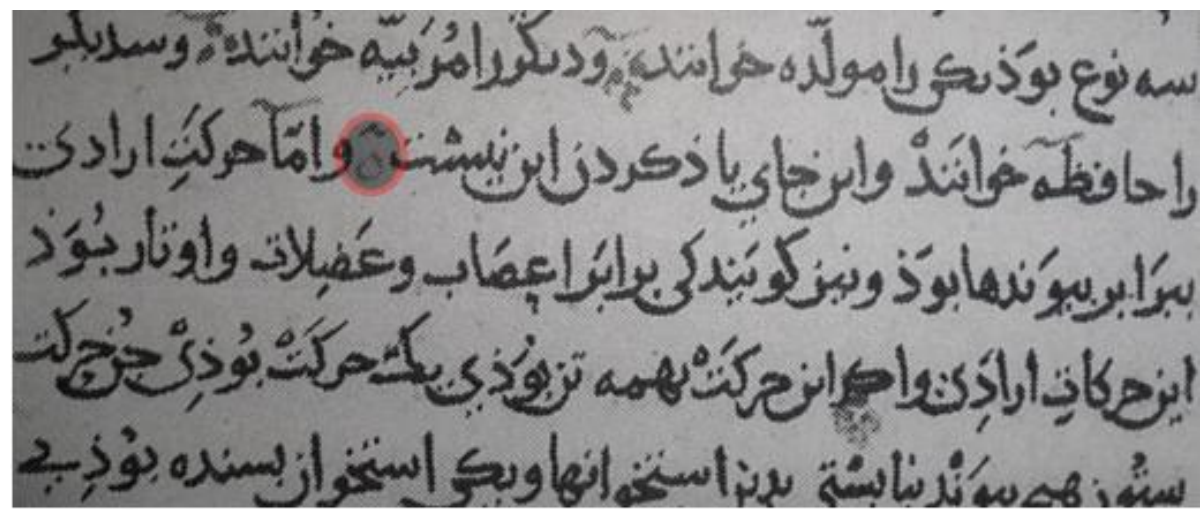

-The sign like four dots which is shaped like a diamond with $(\sim)$ on its top to make a short pause between two phrases. 


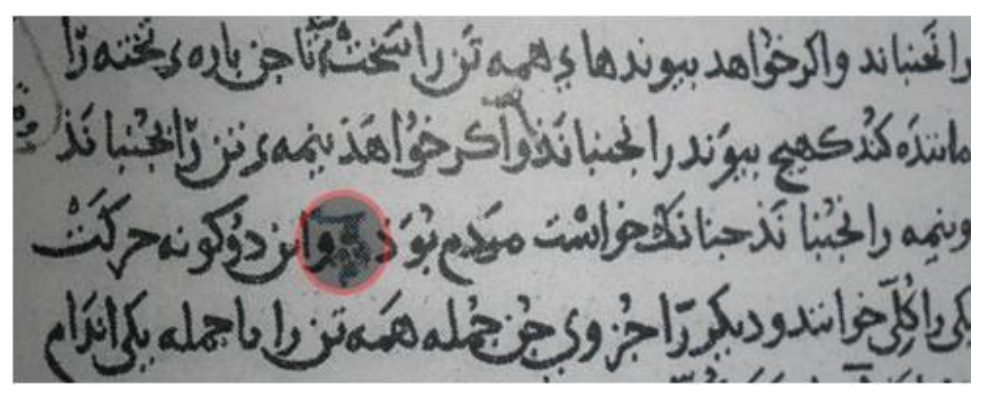

- The sign as a word " l " aتهى " at the end of phrases to show that the subject is finished and the new one will launch.

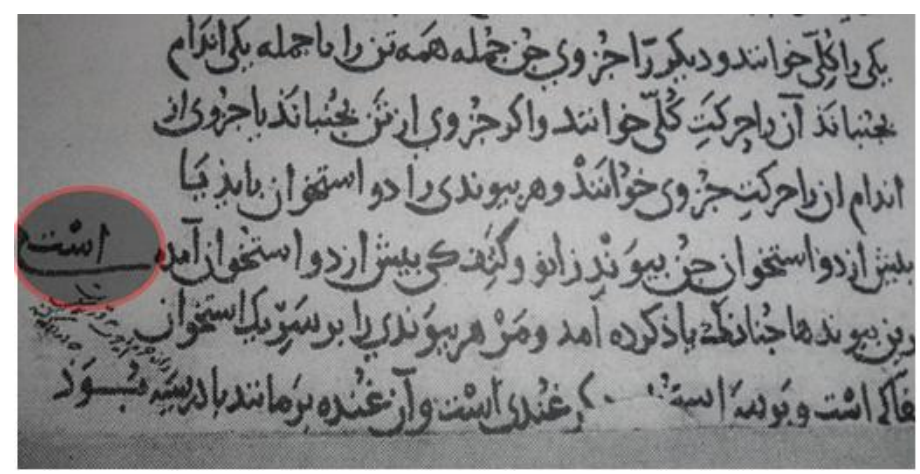

2) "Majmalo Tvarikh va Ghesas" is the other copy which is written by an anonymous author in 520 lunar year. It is inscribed without any signs.

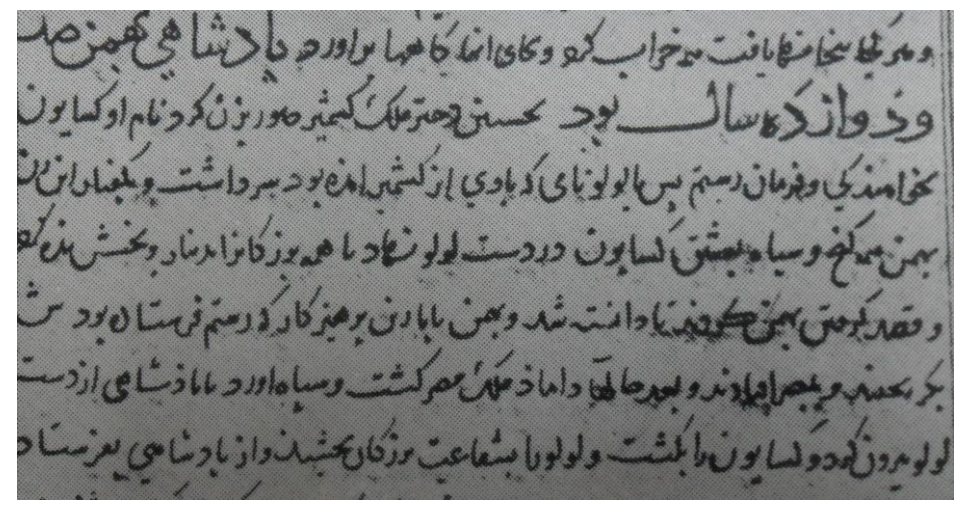

3) "Sovare Kvakeb" is written by Toosi in 647 lunar year. It consists of subjects that are related to astronomy. No specific signs are used in this version.




4) "Majmal aghval fi Hekam va Amsal" by Demanisi written in 693 lunar year. In this copy, the Arabic proverbs are translated into Persian and the signs used in it are as follows:

- The sign like a full circle used to separate the Arabic text from Persian

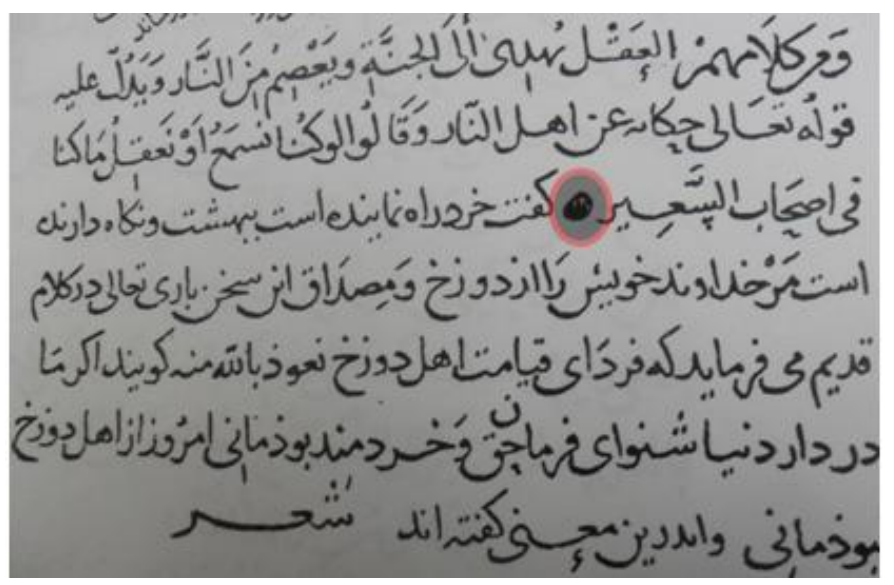

- The sign like two flowers in which there are three dots in the left side and in a circle is used to show the word by word translation of the Arabic text to Persian and also it has the function of decorating of the text.

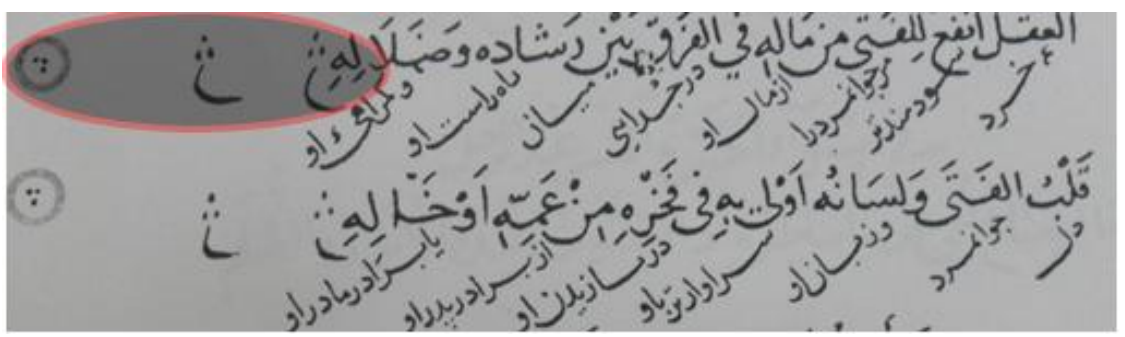

- The sign like a circle in which, there is a black dot and at the left side of it, there is one flower. Sometimes there is just one flower between two circles (without a dot in between). It is used at the end of Arabic phrases and just has a decoration aspect.

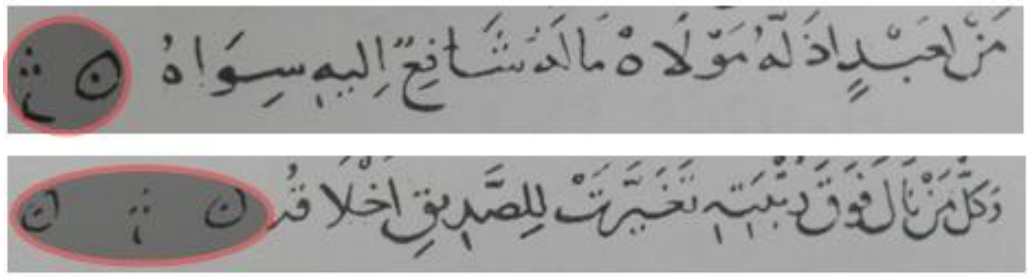

- The sign like two flowers with a space at the end of phrases and is used just for designing the text.

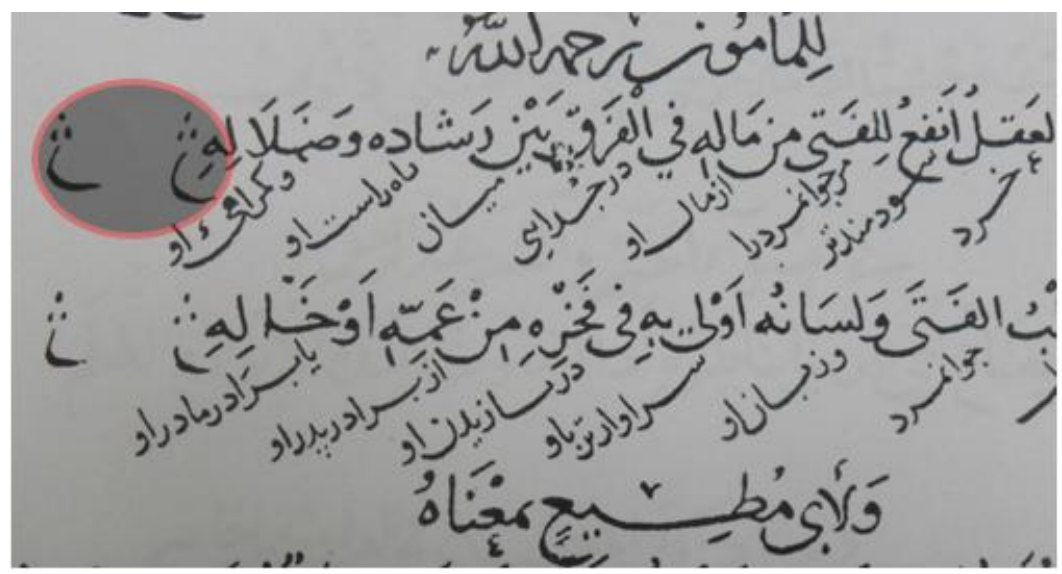

5) "Tajziyato Amsar" known as "Tarikh Vassaf" by Yazdi written in 730 lunar year. It has a historical theme. The signs are: 
- The sign like a flower at the beginning and end of each verse for decorating a poem.

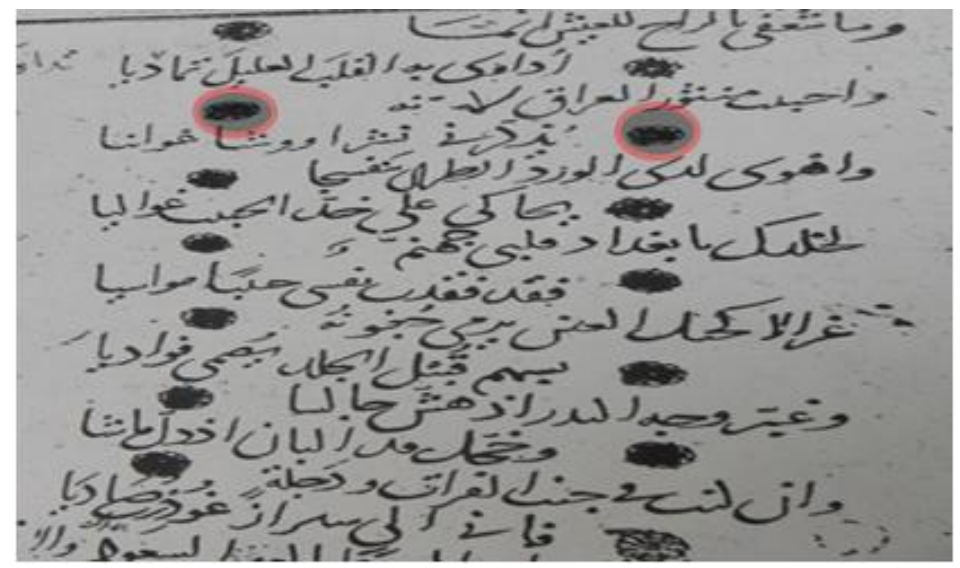

6) "Hezar Hekayate Sufian" with an anonymous author written in 883 lunar year with theosophical themes. The signs are:

- The sign like an eye drop between two verses to make a gap between them.

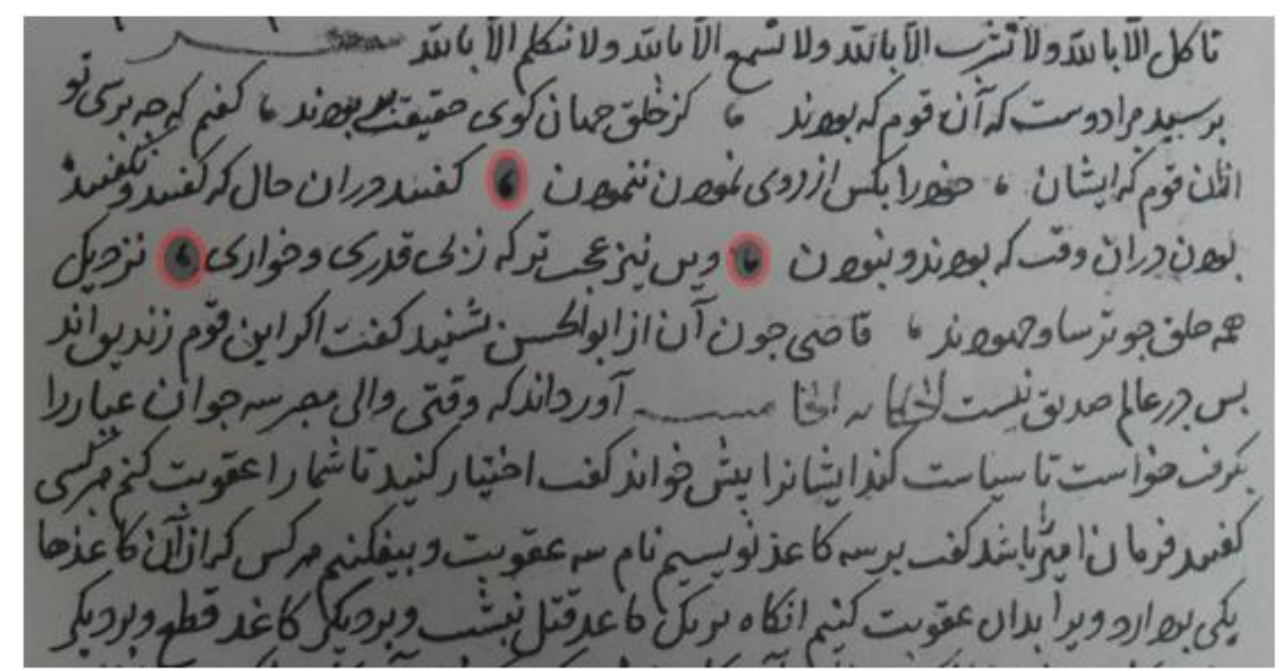

- The sign like an emptied circle between verses to show a gap between them.

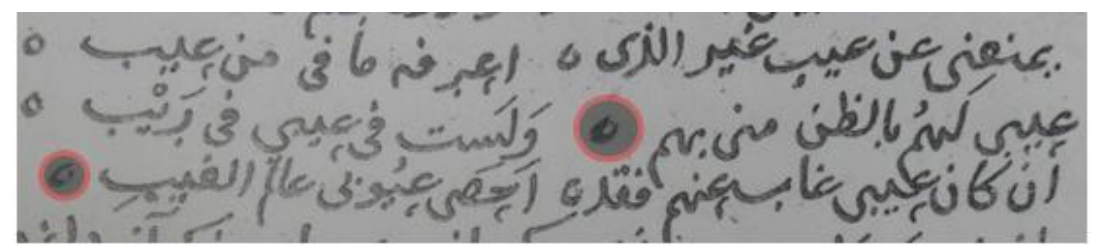

\section{DISCUSSION AND CONCLUSION}

Investigating the six copies with different subjects, revealed that in two copies there is no specific sign used by authors; that is why reading these texts is difficult and leads to misunderstandings. In other copies, the authors attempted to reveal the spoken language characteristics to aid the readers to recognize the appropriate and correct meaning. Therefore, there are some signs in these copies which are rarely used in Persian texts nowadays. They are categorized for applying seven functions:

Most authors used some signs to decorate the text and replete spaces. In recent texts, these signs do not appear and there is no substitution for them. So they are omitted from Persian manuscripts.

Some of the authors tried to reflect their short or long pauses among phrases in their texts by using some signs. In recent texts, comma (‘), semicolon (`) and full stop (.) play the same role.

Attempts are make to show the gap between words, phrases, sentences and verses from each other. Full stop (.), dash (/), underline (-) or sometimes comma (‘) are substituted by these signs in recent texts. 
In some cases the authors make a word or a subject prominent from other parts of text. These signs are used to denote titles, count numbers and key terms. This function is reflected by (" ") in recent years.

In some of these copies, some signs are used to separate Arabic texts from Persian ones. This role is demonstrated by using a blank space between two verses in recent texts.

Sometimes one complete word is used to indicate the final part of a sentence or a paragraph, whereas in recent text $(*$ $* *)$ is used.

Some signs are often used to separate the Persian text from Arabic or irrelevant sentences. (( )) in these days is substituted by these signs.

To wrap up, the numbers of signs used in analyzed photographic copies are realized in fourteen types and we come to the conclusion that using these signs, both their forms and their functions, were not written according to specific rules at that time and it was depended on author's interests, tastes and styles. It reveals that writer's felt such requirement in their writings and tried to solve the probable problems, but because of not having universal rules, they used these signs according to their interest. On the other side, there is one salient point about comma that it is the only sign that existed from ancient times but has different functions nowadays. It means that this sign was present in Persian writings earlier than other signs and also unlike other signs, was not imported from foreign language to this language.

\section{REFERENCES}

[1] Adibsoltani, SH. (1987). How to Write a Book. Tehran: Sazman Entesharat va Amuzesh Enghelab Eslami.

[2] Ahmadigivi, H. (2001). Language and Edition in Persian. Tehran: Samt press.

[3] Amini, K. (2010). The Rule of Writing. Tehran: Moasse Ali Amuzesh va Pazuhesh Modiriyat va Barnamerizi.

[4] Atashparvar, H. (1982). Common Signs in Persian Text. Mashhad: Atlas Press.

[5] Bacon, B. (1924). Punctuation, Translation, Interpretation. The Journal of Religion. Vol. 4, No.3: 243 - 260.

[6] Ghorbaniyun, H. (2005). The Method of Representing the Written and Spoken Points. Mashhad: Jam Aria Press.

[7] Johnson, E. (1954). A Simpler Approach to Punctuation. College English. Vol. 15, No. 7: 399 - 404.

[8] Kakhi, M. (2000). The Method of Writing. Tehran: Amir Kabir Press.

[9] Khayam, M. (1955). Future Written Language. Tehran: Negah Press.

[10] Mansuri, H. (1997). Composition and Writing a Letter. Tehran: Mehrdad Press.

[11] Masaheb, GH. (1967). Persian Encyclopedia. Tehran: Feranklin Press.

[12] Moein, M. (1995). Dehkhoda Encyclopedia. Tehran: Tehran University Press.

[13] Salisbury, R. (1939). The Psychology of Punctuation. The English Journal. Vol. 28, No. 10: 794 - 806.

[14] Samiee, A. (2007). Record and Edition. Tehran: Samt Press.

[15] Singleton, R. (1944). How to Teach Punctuation. College English. Vol. 6, No. 2, $111-115$.

[16] Solomon, M. (1990). The Power of Punctuation. Design Issues. Vol. 6, No. 2, 28-32

[17] Sparks, M. (1953). A Practical Approach to Punctuation. The English Journal. Vol. 42, No.3: 158 - 159.

[18] Zolfaghari, H. (1999). How to Write a Composition. Tehran: Asatir Press.

[19] Yahaghi, M. (2005). The Guidance for Edition. Mashhad: Astane Ghods Press.

Azam Estaji is associate professor in linguistics. She is currently in Ferdowsi University of Mashhad, where she teaches Historical linguistics, Phonology, Phonetics and Pragmatics. She has published more than 40 articles in different journals. His major interests are: Phonology, Pragmatics and Forensic.

Ailin Firooziyan Pooresfahani is an MA holder in linguistics. She has done her study in Ferdowsi University of Mashhad. Her major interests are: Pragmatics, Phonology and Morphology. 